\title{
MODELING THE THERMAL MECHANICAL BEHAVIOR OF A 300 K VACUUM VESSEL THAT IS COOLED BY LIQUID HYDROGEN IN FILM BOILING
}

\author{
S. Q. Yang, M. A. Green, and W. Lau
}

Oxford University Department of Physics, Oxford OX1 3RH, United Kingdom

\begin{abstract}
This report discusses the results from the rupture of a thin window that is part of a 20 -liter liquid hydrogen vessel. This rupture will spill liquid hydrogen onto the walls and bottom of a $300 \mathrm{~K}$ cylindrical vacuum vessel. The spilled hydrogen goes into film boiling, which removes the thermal energy from the vacuum vessel wall. This report analyzes the transient heat transfer in the vessel and calculates the thermal deflection and stress that will result from the boiling liquid in contact with the vessel walls. This analysis was applied to aluminum and stainless steel vessels.
\end{abstract}

\section{INTRODUCTION}

The proposed Muon Ionization Cooling Experiment (MICE) [1] has three liquid hydrogen absorbers that remove both the transverse and longitudinal momentum from a muons beam with an average momentum of about $200 \mathrm{MeV} / \mathrm{c}$. Eight 201-MHz RF-cavities accelerate the muons back to their original longitudinal momentum without adding their back the transverse momentum lost in the cooling process. Liquid hydrogen has been selected as an absorber material because it has twice the $\mathrm{dE} / \mathrm{dx}$ (energy loss per unit mass per square meter) of any other material. Hydrogen has only single proton in its nucleus. Thus, the coulomb scattering, which reintroduces transverse momentum into the muons, is minimized. Hydrogen is the best material for muon ionization cooling by a factor of two.

For safety reasons, the $\mathrm{LH}_{2}$ vessel must be surrounded by a vacuum that is blanketed from the outside air by an inert gas shield. This vacuum is separated from any of the other vacuum systems in MICE. This means that the muons must pass through four windows, two on the absorber vessel and two on the absorber vacuum vessel. These windows, which are made from a high $\mathrm{z}$ material (compared to hydrogen), will contribute to the coulomb scattering that produces of transverse momentum in the beam. Very thin windows must be made from a low z material. Of the low z materials available, only beryllium, magnesium and aluminum can be used for vacuum leak tight thin windows. MICE will use 180-mm thick 6061-T6 aluminum windows on both vessels. These windows have a design burst pressure of 0.68 $\mathrm{MPa}$.

This report discusses the safety implications that result from the rupture of a liquid hydrogen thin window. A rupture will result in 20-liters liquid hydrogen ending up in the absorber vacuum vessel [2]. The liquid hydrogen spills onto the walls and bottom of the $300 \mathrm{~K}$ absorber vacuum vessel with dome shaped heads. Some of the spilled hydrogen will be splashed onto the $300 \mathrm{~K}$ aluminum vacuum windows. The spilled hydrogen boils removing thermal energy from the vessel walls and the windows.

Figure 1 shows a cross-section of the MICE focusing magnet with a liquid hydrogen absorber installed within the magnet warm bore. Figure 1 shows where the liquid hydrogen ends up when a liquid hydrogen window is ruptured. A window rupture at either end of the absorber will result in a liquid hydrogen pool on the bottom of the absorber vacuum vessel at the lowest point. A hydrogen window rupture can also result in liquid hydrogen flowing along the magnet warm bore. A rupture at either end will result in splashing the hydrogen on a vacuum window. The boiling hydrogen will pressurize the absorber vacuum vessel to until the pressure can be relieved through a relief device. This report shows a FEA analysis of the transient heat transfer into the $300 \mathrm{~K}$ vessel walls and the thin windows. The thermal deflections and stress that result from the contact with boiling liquid hydrogen are calculated for the time that the liquid hydrogen is in contact with the wall or window. The thermal and stress analysis was applied to vacuum vessels fabricated from 6061-aluminum and 304-stainless steel. 


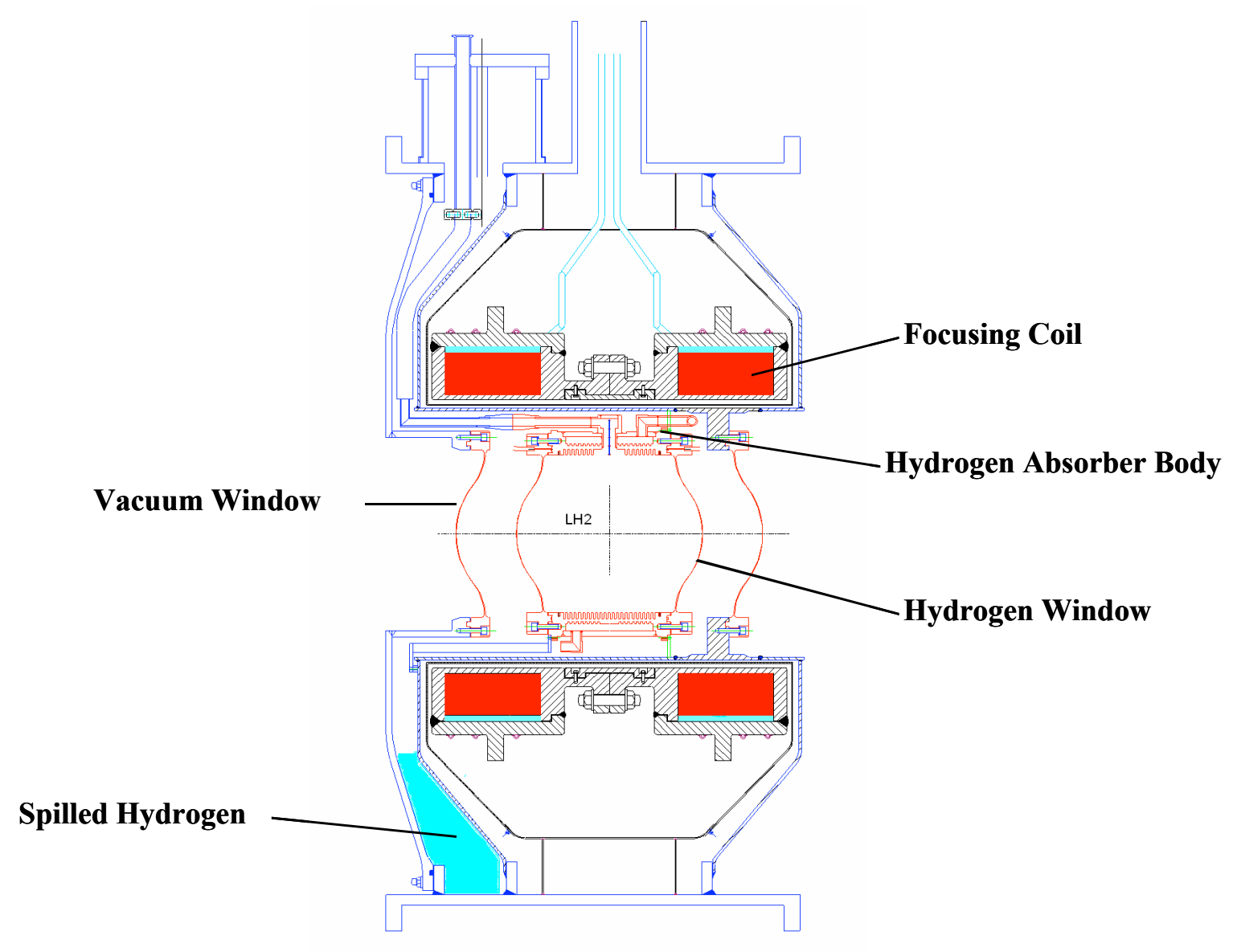

Figure 1. Cross-section of the MICE absorber focus module showing the liquid hydrogen after a window rupture.

\section{WALL THERMAL TIME CONSTANTS AND BOILING HEAT TRANSFER}

In order to determine the rate that cold is transferred through the metal in contact with the hydrogen one should look at the thermal diffusivity and the thermal penetration depth for the cryostat material. Since the temperature change for the vessel is relatively small, the room temperature values for the thermal diffusivity and thermal penetration time constants can be used to judge the problem.

The thermal penetration depth $\square$ as a function of time $t$ is directly related to the thermal diffusivity $\square$. An expression for the thermal penetration depth in a solid $\square(t)$ is given as follows [3]:

$$
\square(t)=(\square t)^{0.5}=\frac{\square k t}{\square \square c} \stackrel{\square}{0.5}^{\square .5}
$$

where $\mathrm{k}$ is the material thermal conductivity; $\square$ is the material density; and $\mathrm{c}$ is the material specific heat. For 6061 Aluminum, $\mathrm{k}=180 \mathrm{~W} \mathrm{~m}^{-1} \mathrm{~K}^{-1} ; \square=2713 \mathrm{~kg} \mathrm{~m}^{-3} ; \mathrm{c}=963 \mathrm{~kJ} \mathrm{~kg}^{-1}$; and $\square=6.89 \times 10^{-5} \mathrm{~m}^{2} \mathrm{~s}^{-1}$. For 304 stainless steel, $\mathrm{k}=14.9 \mathrm{~W} \mathrm{~m}^{-1} \mathrm{~K}^{-1} ; \square=7900 \mathrm{~kg} \mathrm{~m}^{-3} ; \mathrm{c}=477 \mathrm{~kJ} \mathrm{~kg}^{-1}$; and $\square=0.395 \times 10^{-5} \mathrm{~m}^{2} \mathrm{~s}^{-1}$. Since the time constant for the boiling of 20 liters of liquid hydrogen spilled into the absorber vacuum vessel is about $20 \mathrm{~s}$, it is useful to look at the thermal penetration depth for key materials at a time of $20 \mathrm{~s}$. For 6061 aluminum $\square(20)=37.1 \mathrm{~mm}$. For 304L stainless steel $\square(20)=8.9 \mathrm{~mm}$. The thermal penetration depth for aluminum is a factor of four larger than for stainless steel, which suggests that the depth of a rib or a plate is less easily penetrated for the stainless steel.

Thermal deflection is a function of the contraction coefficient $\square$ as well as the temperature difference across a plate. The thermal stress involves the modulus of elasticity $\mathrm{E}$ as well the contraction coefficient and temperature difference across the plate. For 6061 aluminum, $\square=2.15 \times 10^{-5} \mathrm{~K}^{-1}$ and $\mathrm{E}=69 \mathrm{GPa}$. For 304 stainless steel, $\square=1.43 \times 10^{-5} \mathrm{~K}^{-1}$ and $\mathrm{E}=200 \mathrm{GPa}$. 
Since the hydrogen enters the $300 \mathrm{~K}$ vacuum chamber as a liquid, the starting $\square \mathrm{T}$ is $280 \mathrm{~K}$. Since the temperature differences are large, a film boiling equation such as the Breen Westwater equation [4] should be used. For hydrogen, heat flux per unit area for film boiling $[\mathrm{Q} / \mathrm{A}]_{\mathrm{f}}$ can be estimated using the following simplified expression [5];

迎

The linear relationship between film boiling heat transfer per unit area the $\square \mathrm{T}$ between the wall and the bulk hydrogen means that film boiling can be treated just like convection heat transfer. This heat transfer coefficient was applied to the surfaces that are in contact with liquid hydrogen in order to calculate the thermal stress and deflection. When there is 201 of liquid hydrogen in the vacuum vessel, about $0.55 \mathrm{~m}^{2}$ of $300 \mathrm{~K}$ surface is exposed to the liquid. The peak heat flux to the hydrogen is about $51 \mathrm{~kW}$. The peak hydrogen boil off rate is about $0.116 \mathrm{~kg} \mathrm{~s}^{-1}$. All of the hydrogen boils away in just over 20 seconds.

\section{THE FINITE ELEMENT CALULATIONS OF TEMPERATURE, STESS AND DEFLECTION}

A worst-case analysis of the effect of thermal shock was studied for the absorber vacuum vessel end shell. The edges of the end shell are fixed to the end plate flange. Figure 1 shows the depth of the liquid hydrogen as it pools at the end of the absorber vacuum vessel. For the worst-case simulation, the liquid hydrogen was assumed to be in contact with the vacuum vessel end plate at its maximum depth for $20 \mathrm{~s}$. The maximum liquid hydrogen depth is $455 \mathrm{~mm}$. The heat transfer coefficient for the part of the plate in contact with the liquid was $333 \mathrm{~W} \mathrm{~m}^{-2} \mathrm{~K}^{-1}$. The heat transfer coefficient used for the rest of the plate was zero. The study was done for 10-mm thick 304 stainless steel and a 6061 -aluminum end plates. Table 1 shows the calculated maximum temperature change, temperature differences through the shell, the maximum thermal stress, and deformation within the vacuum vessel end plates.

Table 1. The maximum $\square \mathrm{T}$ in the vacuum vessel end plate, the $\square \mathrm{T}$ through the plate, the maximum plate deflection and the maximum thermal stress in the MICE vacuum vessel end plate for hydrogen in contact with the plate for $20 \mathrm{~s}$.

\begin{tabular}{lcc}
\hline Parameter & 304 St Steel & 6061 Aluminum \\
\hline Maximum Temperature Change (K) & 58.8 & 62.4 \\
Temperature Difference Through Shell (K) & 25 & 3.4 \\
Maximum End Shell Displacement (mm) & 0.79 & 1.60 \\
Maximum Stress in the End Shell (MPa) & 176 & 115 \\
\hline
\end{tabular}

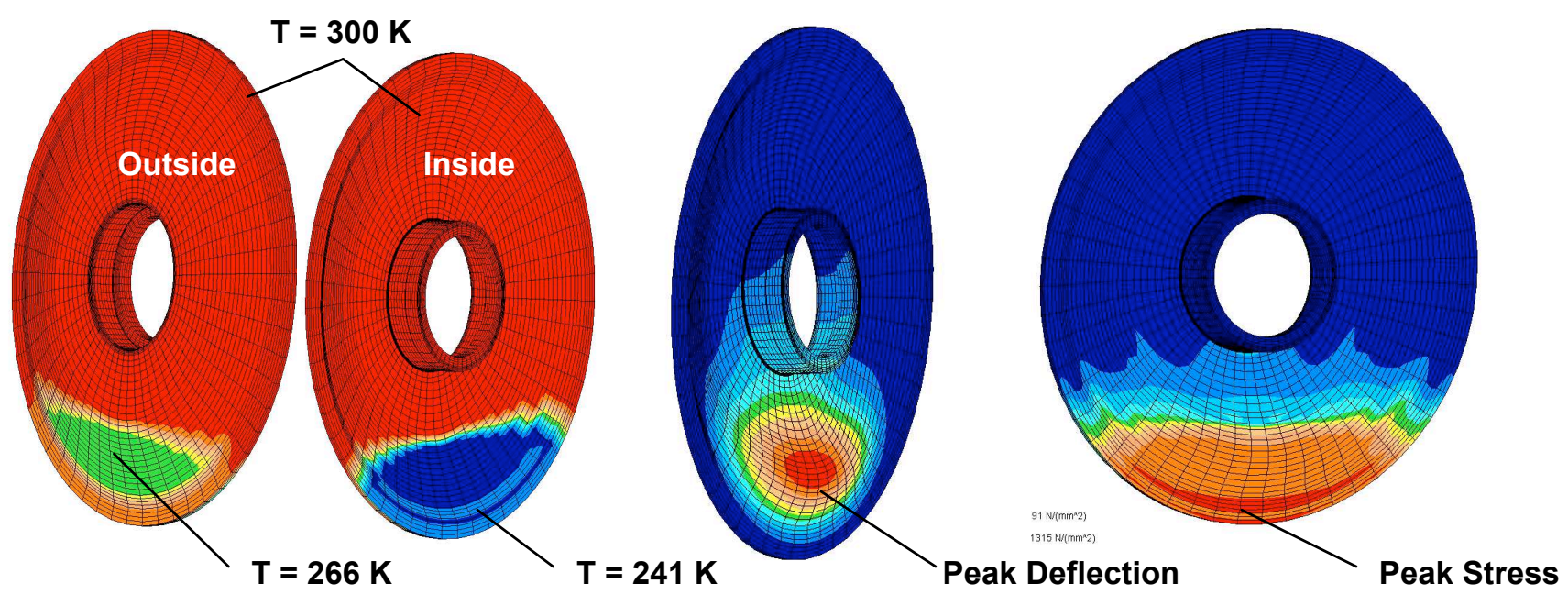

Figure 2. The minimum temperature on the inside and the outside and the peak deflection and stress points due to $\mathrm{LH}_{2}$ spill 

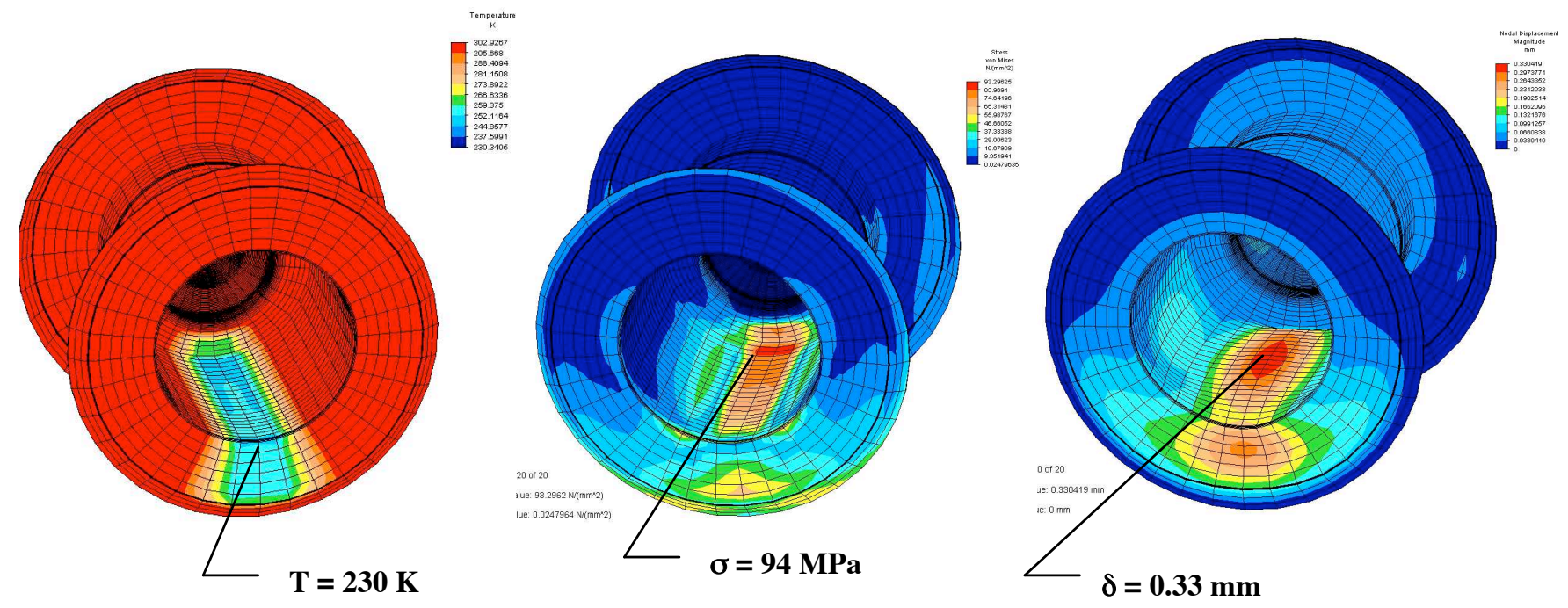

Figure 3. Minimum temperature, peak stress and peak deflection on the magnet warm bore tube due to a $\mathrm{LH}_{2}$ spill in the bore

Figure 2 shows the temperature on the inside and the outside of a 304 stainless steel end shell. Also shown in Figure 2 are the locations of the peak stress and peak deflection points for the stainless steel end shell. The values of the temperature peak stress and peak deflection are given in Table 1.

Figure 3 shows the warm bore and one end of the focusing magnet 304 stainless steel cryostat. For the case shown in Figure 3, the cryostat vacuum vessel was set at $5 \mathrm{~mm}$ and the time of contact for the liquid hydrogen is 10 seconds. As in Figure 2, one can see that the vessel deforms in the direction of the cold hydrogen. The peak stress point is where the inner bore cylinder connects to a stiff ring, upon which one of the vacuum windows is mounted. The minimum temperature point is the lip where the liquid hydrogen runs out of the magnet warm bore.

Splashing liquid hydrogen on the thin windows causes them to deform toward the source of the cold. The levels of stress and deflection in the windows due to thermal gradients are over an order of magnitude lower than the stress and deflection due to pressure.

\section{CONCLUDING COOMENTS}

If the contents of the absorber suddenly spills into the absorber vacuum vessel about $0.55 \mathrm{~m}^{2}$ of the absorber vacuum vessel will be in direct contact with the liquid hydrogen. The maximum heat transfer rate to the liquid hydrogen is about $51.2 \mathrm{~kW}$, which in turn will cause the hydrogen to boil off at the rate of $0.116 \mathrm{~kg} \mathrm{~s}^{-1}$. As long as the inside diameter of the pipe carrying hydrogen gas from the absorber vacuum to the buffer vacuum is larger than $60 \mathrm{~mm}$, the peak pressure drop from the absorber vacuum to the buffer vacuum will be less than 0.3-bar. As a result, the peak pressure in the absorber vacuum should be less than 2-bars during a rupture of an absorber hydrogen window.

\section{ACKNOWLEDGEMENTS}

This work was supported by the Oxford University Physics Department and the Particle Physics and Astronomy Research Council of the United Kingdom.

\section{REFERENCES}

1. "A Proposal to the Rutherford Appleton Laboratory, an International Muon Ionization Cooling Experiment (MICE)," proposed by the MICE Collaboration, 15 December 2002

2. Green, M. A. and Yang S. Q. "The Effect of a Hydrogen Spill inside of a $300 \mathrm{~K}$ Vacuum Vessel on MICE Absorber Hydrogen Safety," an Oxford University Report for the MICE collaboration (2004)

3. Heat Transfer with Applications, Hagen, K. D. Prentice Hall, Upper Saddle River NJ (1999)

4. Breen, B. P. and Westwater, J. W. Chem. Eng. Progress 38, No. 7, p 67 (1962)

5. E. G. Brentari and R. V. Smith, "Nucleate and Film Pool Boiling Design Correlations for $\mathrm{O}_{2}, \mathrm{~N}_{2}, \mathrm{H}_{2}$, and $\mathrm{He}_{\text {, }} \underline{\text { Advances }}$ in Cryogenic Engineering 10, p 325. Plenum Press, New York. USA (1964) 